\title{
A IMPORTÂNCIA DO USO DE AUTORES DOS ESTUDOS DA LINGUAGEM NAS REFERÊNCIAS BIBLIOGRÁFICAS DOS TRABALHOS SOBRE ALFABETIZAÇÃO CIENTÍFICA E LETRAMENTO CIENTÍFICO
}

\author{
THE IMPORTANCE OF THE USE OF AUTHORS FROM LANGUAGE \\ STUDIES IN THE BIBLIOGRAPHIC REFERENCES OF WORKS ON \\ SCIENTIFIC ALPHABETIZATION AND SCIENTIFIC LITERACY
}

Rodrigo Bastos Cunha'

\begin{abstract}
Resumo: O termo "letramento" começou a se difundir no Brasil nos campos da linguística aplicada e do ensino de línguas a partir dos anos 1980. Entre os trabalhos acadêmicos brasileiros que tratam do tema que ficou conhecido internacionalmente como "scientific literacy", a maioria é do campo do ensino de ciências e alguns săo da comunicaçấo ou dos estudos da linguagem. Ainda predomina nesses trabalhos o uso da expressăo "alfabetizaçâo científica", mas tem sido crescente o número de pesquisas que tratam de "letramento científico". Como se trata da apropriaçăo que a área de ensino de ciências faz de conceitos de outra área do conhecimento, buscou-se aqui verificar o quanto os trabalhos sobre "alfabetizaçâo científica" e sobre "letramento científico" se apoiam em autores dos estudos da linguagem em suas referências bibliográficas. Esta pesquisa mostra que o uso de autores dos estudos da linguagem é bem maior nos trabalhos sobre "letramento científico".
\end{abstract}

Palavra-chave: Alfabetizaçăo científica. Ensino de ciências. Ensino de línguas. Estudos da linguagem. Letramento científico.

Abstract: The term "literacy" began to spread in Brazil in the fields of applied linguistics and language teaching from the 1980s. Among the Brazilian academic papers dealing with the topic that became internationally known as "scientific literacy", most are from the field of science teaching and some are from communication or language studies. The use of the term "scientific alphabetization" still predominates in these works, but the number of researches dealing with "scientific literacy" has been increasing. As it deals with the appropriation that the area of science education makes of concepts of another area of knowledge, we sought here to verify how much the works on "scientific alphabetization" and on "scientific literacy" are based on authors of the studies of the

1 Doutor em Linguística Aplicada. Professor do Mestrado em Divulgaçáo Científica e Cultural e coordenador da Especializaçáo em Jornalismo Científico na Universidade Estadual de Campinas (Unicamp).E-mail: rbcunha@unicamp.br 
language in their bibliographic references. This research shows that the use of authors of language studies is much greater in the work on "scientific literacy".

Keywords: Language studies. Language teaching. Science teaching. Scientific alphabetization. Scientific literacy.

\section{INTRODUÇÃO}

O número de trabalhos acadêmicos dos campos da educaçăo científica e do ensino de ciências no Brasil que usam conceitos-chave dos estudos da linguagem e do ensino de línguas - alfabetizaçâo e letramento - é relativamente grande. Iremos abordar, neste artigo, as relaçooes entre o termo inglês "literacy" e o termo "letramento", as justificativas dos autores dos estudos da linguagem e do ensino de línguas para a emergência desse novo termo para designar algo além da alfabetizaçăo e a importância que a escolha de um dos termos - alfabetizaçâo ou letramento - tem para a educaçăo científica e o ensino de ciências. Apresentaremos, a seguir, um levantamento dos trabalhos sobre alfabetizaçăo científica e sobre letramento científico publicados nos últimos dez anos. Entre os artigos publicados em periódicos e os trabalhos apresentados em congressos científicos, mostraremos, ao final, o quanto essas pesquisas se apoiam em autores dos estudos da linguagem.

Antes, vejamos como essa mesma relaçâo entre ensino de ciências e estudos da linguagem é estabelecida em língua inglesa. Um artigo publicado por Stephen Norris e Linda Phillips, da Faculdade de Educaçáo da Universidade de Alberta, no Canadá, mostra, já em seu título, a importância que tem um conceito cunhado nos estudos da linguagem e no ensino de línguas quando ele é tomado de empréstimo pelos estudos do campo da educaçâo científica e do ensino de ciências: "How literacy in its fundamental sense is central to scientific literacy" (NORRIS e PHILLIPS, 2003).

Esses autores observam que "o objetivo educacional do letramento científico tem um propósito em comum com os objetivos do letramento em outras áreas do conhecimento" (NORRIS e PHILLIPS, 2003, p. 233). As capacidades de compreensáo, interpretaçấo, análise e crítica requeridas para lidar com um texto sobre ciência, segundo eles, seriam as mesmas requeridas para lidar com textos com diferentes conteúdos. Norris e Phillips consideram que a leitura envolve mais do que conhecer as palavras e localizar informaçāo em um texto:

Inferir significados a partir do texto envolve a integraçăo da informaçăo do texto ao conhecimento do leitor. Através dessa integraçăo, algo novo, a mais e além do texto e do conhecimento do leitor, é criado - uma interpretaçăo do texto ... nem toda interpretaçấo de um texto é igualmente boa, mas geralmente há mais de uma boa interpretaçăo. (NORRIS; PHILLIPS, 2003, p. 228)

Essa concepçâo coincide com a de Ezequiel da Silva (1979, p. 4), para quem "os atos de refletir e de transformar, sem dúvida alguma, devem fazer parte da atividade de leitura". Segundo ele, qualquer texto é uma possibilidade que depende da experiência prévia do leitor que o confronta, e sua leitura é sempre aberta a transformaçôes. De acordo com esse autor, "na transformaçấo, o sujeito responde aos horizontes evidenciados, reelaborando-os em termos de novas possibilidades" (SILVA, 1979, p. 63-68). Em outro trabalho, Silva chama esse processo de "reescritura", e aponta que 
vários fatores de ordem psicológica e linguística, além dos contextuais, săo mobilizados na fase de (re)criaçáo de um texto ... ao ler, o sujeito-leitor sempre mobiliza outros textos presentes na sua história de vida e, após a interlocuçăo, produz um outro texto que é a expressăo do sentido que ele conseguiu arquitetar para o texto original. (SILVA, 2003, p. 46-47)

A multiplicidade de interpretaçóes de um texto apontada por Norris e Phillips (2003) toca em um ponto que afeta náo apenas o ensino de ciências, mas o de todas as disciplinas: a noçăo de leitura certa ou errada. O linguista Sírio Possenti lembra que "ao se discutir por que alguém leu um texto como leu, uma das possibilidades a ser contemplada é que se conclua que o leitor pode ter manobrado mal" (POSSENTI, 1999, p. 173). Ele observa, no entanto, que "se você acredita que existem leituras erradas, pode também ser acusado de acreditar que só há uma leitura correta". Isso, segundo ele, seria uma "inferência equivocada, pois o que se pode muito bem concluir é que se há algumas erradas pode haver algumas corretas" (POSSENTI, 1999, p. 174).

\section{LITERACY E LETRAMENTO}

No Brasil, o termo "literacy" já vem sendo traduzido há três décadas como "letramento" nos campos dos estudos da linguagem e do ensino de línguas. De acordo com Soares (1998), novas demandas sociais de uso da escrita requeriam um novo termo, o qual representa um processo com diferentes níveis de complexidade e se contrapóe à dicotomia simplista entre o analfabeto e o alfabetizado. Soares (1998, p. 70) explica que "as habilidades de escrita, tal como as de leitura, devem ser aplicadas diferenciadamente à produçáo de uma variedade de materiais escritos: da simples assinatura do nome ou elaboraçâo de uma lista de compras até a redaçâo de um ensaio ou de uma tese de doutorado". Ainda segundo essa autora (SOARES, 1998, p. 70-71),

[...] as competências que constituem o letramento săo distribuídas de maneira contínua, cada ponto ao longo desse contínuo indicando diversos tipos e níveis de habilidades, capacidades e conhecimentos, que podem ser aplicados a diferentes tipos de material escrito. Em outras palavras, o letramento é uma variável contínua, e năo discreta ou dicotômica. Portanto, é difícil especificar, de uma maneira náo arbitrária, uma linha divisória que separaria o indivíduo letrado do indivíduo iletrado. (grifos da autora)

De acordo com Kleiman (1995), o termo "letramento" se refere a efetivas práticas sociais de uso da escrita que se dăo em contextos diversos e através de diferentes agências de letramento além da escola. Essa autora alerta que

[...] uma vez que os grupos nâo-letrados ou nấo-escolarizados săo comparados com grupos letrados ou escolarizados, estes últimos podem vir a ser a norma, o esperado, o desejado, principalmente porque os pesquisadores săo membros de culturas ocidentais letradas. Quando a comparaçáo é realizada, estamos a um passo de concepçóes deficitárias de grupos minoritários..., concepçōes estas perigosas pois podem fornecer argumentos para reproduzir o preconceito, chegando até a criar duas espécies, cognitivamente distintas: os que sabem ler e escrever e os que náo sabem. (KLEIMAN, 1995, p. 25-26) 
Embora o termo "letramento" tenha ganhado força nos campos da linguística aplicada e do ensino de línguas, desde que começou a ser empregado, na segunda metade da década de 1980, outras áreas do conhecimento, como a da educaçăo científica e ensino de ciências, traduzem "literacy", na maioria das vezes, como alfabetizaçăo, e apenas uma minoria traduz como letramento. Embora tenham correlaçăo, esses termos náo săo sinônimos, e a escolha do termo emprestado dos estudos da linguagem afeta a noçăo que se quer discutir no campo da educaçăo científica: a alfabetizaçăo científica ou o letramento científico.

\section{ALFABETIZAÇÃO, LETRAMENTO E ENSINO DE CIÊNCIAS}

Em artigo recente (CUNHA, 2017), eu trato das implicaçōes políticas da interpretaçáo de "scientific literacy" no modelo de ensino de ciências. Apesar de alguns trabalhos que tratam de alfabetizaçáo científica usarem Paulo Freire como referência bibliográfica, autor que defende uma alfabetizaçăo emancipatória, esse artigo mostra que, em geral, os autores que optam pelo uso de alfabetizaçâo científica assumem uma postura autoritária de ensino, impondo o conhecimento científico como sendo o único legítimo para a leitura do universo - mesmo que náo se deem conta disso.

Um trabalho anterior (CUNHA, 2015), que fiz a partir do levantamento de pesquisas sobre "alfabetizaçâo científica" e sobre "letramento científico" publicadas em 2014 , já sinalizava uma substancial diferença em relaçáo ao uso de autores dos estudos da linguagem e do ensino de línguas nas referências bibliográficas. Dentre as 10 pesquisas sobre "alfabetizaçâo científica" analisadas, apenas uma faz citaçăo a um autor dos estudos da linguagem. Já entre as 10 pesquisas que tratam de "letramento científico" analisadas, sete citam autores dos estudos da linguagem, entre eles Angela Kleiman, Roxane Rojo e Joăo Wanderley Geraldi² além de Brian Street, autor de língua inglesa, e Magda Soares, autora da área da Educaçấo, graduada em Letras, e uma das principais referências brasileiras sobre "letramento" e "alfabetizaçăo".

Apresentarei a seguir os resultados de uma pesquisa que amplia o escopo do levantamento para os últimos dez anos, verificando os resultados da busca no Google Acadêmico por trabalhos que contenham as expressóes "alfabetizaçăo científica" e "letramento científico" no período de 2007 a 2016. Nessa pesquisa, busquei verificar o tipo de trabalho publicado (artigo em periódico, trabalho em evento, trabalho de conclusâo de curso, dissertaçăo de mestrado, tese de doutorado, capítulo de livro) e o nível de escolaridade completo ou em curso dos autores dos trabalhos no momento da publicaçăo (graduaçăo, mestrado, doutorado). Dentre os artigos em periódicos e trabalhos em eventos, busquei verificar se as referências bibliográficas apresentavam trabalhos em inglês sobre "scientific literacy" e trabalhos dos estudos da linguagem e ensino de línguas.

2 Kleiman e Rojo atuam no campo dos estudos do letramento. Geraldi, embora nâo trate propriamente de letramento, é citado pelo livro O texto na sala de aula, por ele organizado. O trabalho que tem Geraldi nas referências bibliográficas - além de Kleiman, Rojo - é sobre textos da revista Ciência Hoje das Crianças no letramento escolar. 


\section{OS ESTUDOS SOBRE ALFABETIZAÇÃO CIENTÍFICA E LETRAMENTO CIENTÍFICO}

A busca no Google Acadêmico pela expressâo "alfabetizaçăo científica" para o período de 2007 a 2016, excluindo patentes e citaçóes, resulta em mais de 6.000 trabalhos. Entre esses resultados da busca, aparecem resumos, resenhas e editoriais, que foram excluídos do levantamento. Apenas trabalhos completos foram incluídos.

Como a expressăo "alfabetizaçăo científica" pode ser usada no corpo de um trabalho ou mesmo aparecer na referência bibliográfica utilizada sem que isso necessariamente implique que ela seja central para aquela pesquisa, utilizei como critério de seleçâo a obrigatoriedade de os trabalhos apresentarem a palavra "alfabetizaçāo" no título, no resumo ou nas palavras-chave. $O$ fato de essa expressáo aparecer no título, no resumo ou nas palavras-chave denota uma escolha do pesquisador por "alfabetizaçăo" e nâo por "letramento". Muitos trabalhos mencionam ambas as expressóes e utilizam referência bibliográfica tanto de autores que escolhem "alfabetizaçăo científica", como Chassot (2003), quanto "letramento científico", como Santos (2007)³. Por isso, o critério de selecionar apenas os trabalhos com o termo "alfabetizaçăo" no título, no resumo ou nas palavras-chave se mostra fundamental para distinguir a mera mençăo ao termo da escolha proposital e interessada do termo.

Há ainda autores que năo se posicionam quanto à escolha da expressăo e utilizam tanto "alfabetizaçấo" quanto "letramento" no título, no resumo ou nas palavras-chaves. Esses trabalhos em que náo há um posicionamento claro e ambas as expressôes aparecem năo foram incluídos no levantamento.

O mesmo procedimento foi utilizado na busca no Google Acadêmico pela expressăo "letramento científico" no período de 2007 a 2016. Apenas trabalhos completos com o termo "letramento" no título, no resumo ou nas palavras-chave foram selecionados. A escolha de se usar apenas "letramento" como critério de seleçâo, ao invés de "letramento científico", foi fundamental para ampliar o número de trabalhos selecionados sobre esse tema, possibilitando a inclusáo de estudos sobre temas correlatos ao letramento científico, como letramento acadêmico, letramento digital, letramento estatístico, entre outros. Além disso, um dos trabalhos mais citados entre os que tratam de letramento científico (SANTOS, 2007) tem como título “Educaçâo científica na perspectiva de letramento como prática social", ou seja, utiliza apenas o termo "letramento", isoladamente, mas trata sem dúvida alguma de "letramento científico".

Com o auxílio da Plataforma Lattes, verifiquei o nível de escolaridade de todos os autores no momento da publicaçấo dos trabalhos, quando essa informaçăo nâo estava presente no trabalho publicado. Nos casos de homonímia ou de ausência de currículo Lattes, utilizou-se a busca pela formaçăo acadêmica do autor no site Escavador (www. escavador.com).

3 Attico Chassot e Wildson dos Santos săo os autores com maior número de citaçôes entre os trabalhos do campo da educaçâo científica e do ensino de ciências que tratam de alfabetizaçâo científica ou de letramento científico. 
Entre os artigos publicados em periódicos e os trabalhos apresentados em eventos, procurei verificar se havia nas referências bibliográficas trabalhos sobre scientific literacy e trabalhos de autores dos estudos da linguagem.

\section{RESULTADOS}

Na busca por "letramento científico", foram encontradas 106 pesquisas com o termo "letramento" no título, no resumo ou nas palavras-chave publicadas entre 2007 e 2016, as quais se distribuem da seguinte forma:

Tabela 1: Pesquisas sobre “letramento científico" publicadas entre 2007 e 2016.

\begin{tabular}{l|c}
\hline Trabalhos em eventos & 45 \\
\hline Artigos e periódicos & 33 \\
\hline Dissertações de mestrado & 17 \\
\hline Teses de doutorado & 6 \\
\hline Trabalhos de conclusão de curso & 4 \\
\hline Capítulo de livro & 1 \\
\hline
\end{tabular}

Fonte: Google Acadêmico.

A escolaridade dos 234 autores desses trabalhos ficou assim distribuída:

Gráfico 1: Nível de escolaridade completo ou em curso dos autores dos trabalhos sobre "letramento científico" publicados entre 2007 e 2016.

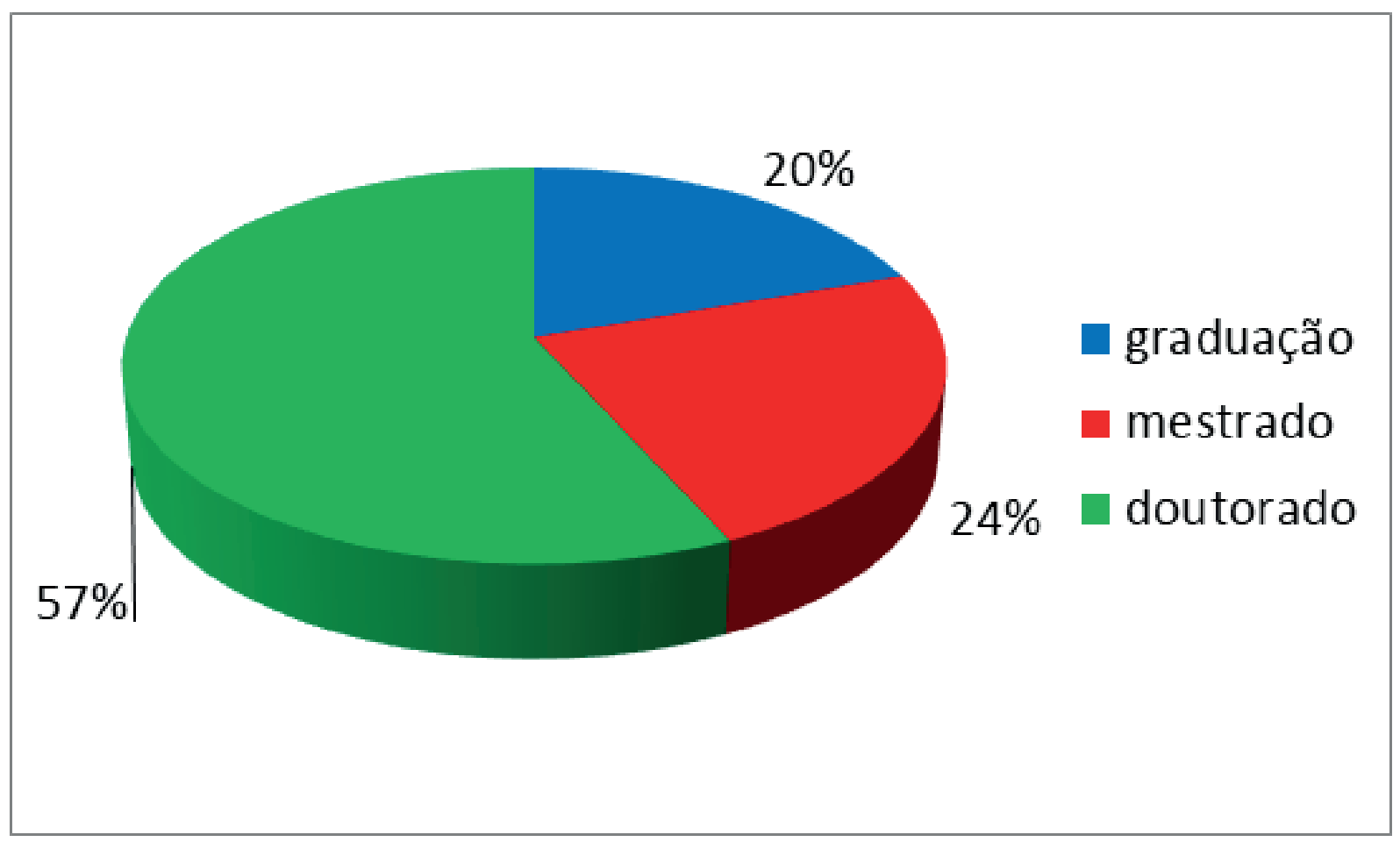

Fontes: Plataforma Lattes/CNPq e Escavador (www.escavador.com) 
Já na busca por "alfabetizaçăo científica", foram encontradas 116 pesquisas com o termo "alfabetizaçăo" no título, no resumo ou nas palavras-chave publicadas no mesmo período, distribuídas assim:

Tabela 2: Pesquisas sobre "alfabetizaçăo científica" publicadas entre 2007 e 2016.

\begin{tabular}{l|c}
\hline Trabalhos em eventos & 32 \\
\hline Artigos e periódicos & 63 \\
\hline Dissertações de mestrado & 15 \\
\hline Teses de doutorado & 4 \\
\hline Trabalhos de conclusão de curso & 2 \\
\hline
\end{tabular}

Fonte: Google Acadêmico.

A escolaridade dos 249 autores desses trabalhos é a seguinte:

Gráfico 2: Nível de escolaridade completo ou em curso dos autores dos trabalhos sobre “alfabetizaçăo científica" publicados entre 2007 e 2016.

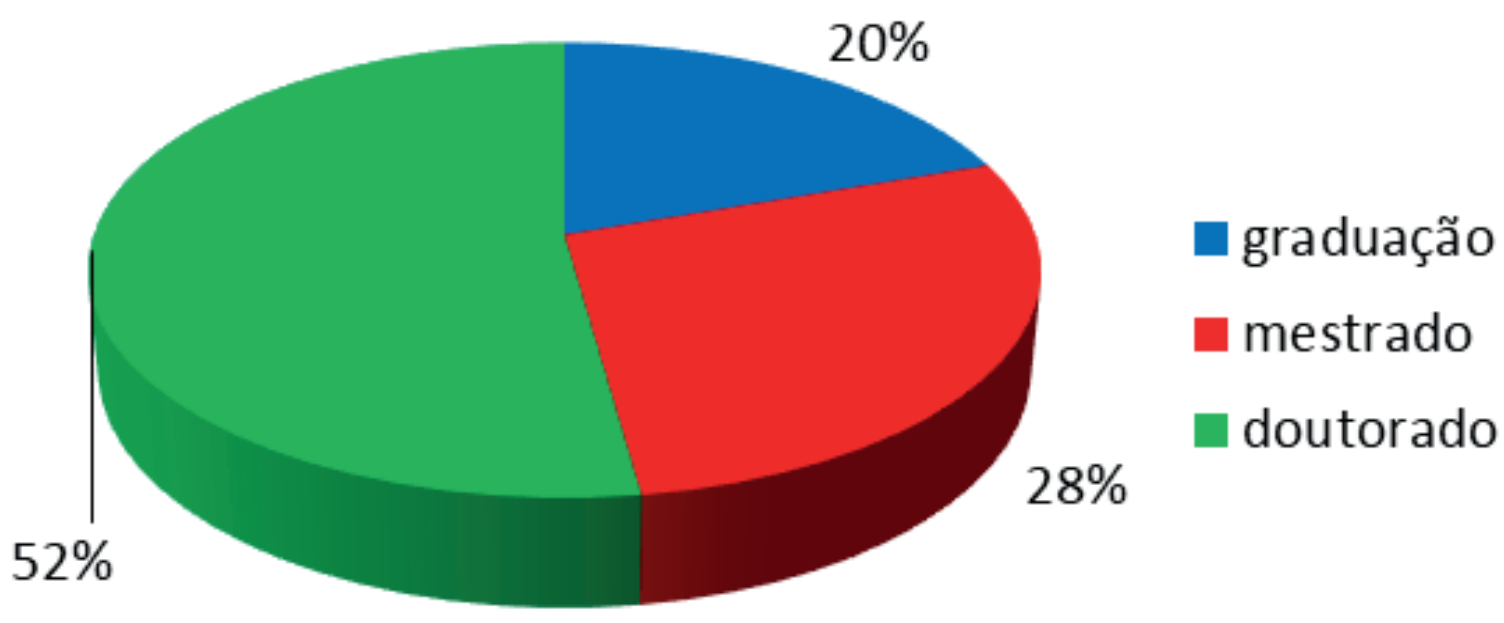

Fontes: Plataforma Lattes/CNPq e Escavador (www.escavador.com)

É de se esperar que haja um predomínio de trabalhos no âmbito da pós-graduaçăo, em que a cobrança por publicaçăo é maior. O fato de haver mais doutores entre os autores se deve à grande quantidade de trabalhos em que os orientadores assinam em coautoria com seus orientandos. Embora o percentual de doutores seja ligeiramente maior nos trabalhos sobre "letramento" (57\%) do que nos trabalhos sobre "alfabetizaçăo" 
(52\%), no período analisado, esse dado isolado năo é suficiente para apontar uma maior especializaçăo de um grupo em relaçăo ao outro.

Os trabalhos mais recentes, contudo, sinalizam uma tendência que merece ser destacada: em 2014 e em 2015, foram publicados mais trabalhos sobre "letramento" do que trabalhos sobre "alfabetizaçáo", e dentre os trabalhos sobre "letramento", o percentual de doutores foi de $67 \%$ em 2014 e de $68 \%$ em 2015 . O número de trabalhos sobre "alfabetizaçăo" teve um crescimento em 2016, mas o percentual de doutores entre seus autores ficou em 32\% naquele ano. Já o número de trabalhos sobre "letramento" permaneceu em 2016 dentro da média dos dois anos anteriores e o percentual de doutores naquele ano continuou acima dos $50 \%$.

Entre os trabalhos apresentados em eventos e artigos publicados em periódicos, o percentual de citaçâo de trabalhos sobre "scientific literacy" é bem próximo nas pesquisas sobre "alfabetizaçăo científica" e sobre "letramento científico". A diferença mais relevante está na traduçâo que se faz de "literacy" e nas interpretaçóes desse termo. Dentre os trabalhos com "alfabetizaçăo" no título, no resumo ou nas palavras-chave, 33\% citam trabalhos sobre "scientific literacy"; nos trabalhos com "letramento" no título, no resumo ou nas palavras-chave, o índice é de 35\%.

Já em relaçăo à citaçâo de autores dos estudos da linguagem, o índice é bem maior nos trabalhos sobre "letramento" do que nos trabalhos sobre "alfabetizaçáo". Isso sugere que a escolha por "letramento", provavelmente, se apoia na centralidade desse termo para a noçâo de "letramento científico", assim como "literacy" é central para a noçâo de "scientific literacy" (NORRIS e PHILLIPS, 2003). Enquanto 54\% dos trabalhos sobre "letramento científico" com "letramento" no título, no resumo ou nas palavras-chave citam autores dos estudos da linguagem, nos trabalhos sobre "alfabetizaçâo científica" com "alfabetizaçáo" no título, no resumo ou nas palavras-chave, esse índice cai para $22 \%$. Do total de trabalhos sobre "letramento científico" que citam autores dos estudos da linguagem, 61\% dos autores eram doutores ou estavam cursando o doutorado no momento da publicaçâo da pesquisa.

\section{DISCUSSÃO}

A maioria dos trabalhos brasileiros nos campos da educaçăo científica e do ensino de ciências que trata de alfabetizaçáo científica se apoia mais em autores do mesmo campo do conhecimento que já trataram do mesmo tema anteriormente. Entre os trabalhos com maior número de citaçôes estâo Chassot (2003) e Lorenzetti e Delizoicov (2001).

Nesses trabalhos, a escolha dos pesquisadores de ensino de ciências pelo termo "alfabetizaçâo" pressupôe um analfabetismo entre aqueles que nâo possuem um tipo de conhecimento específico, o científico, o qual é tido, por esses autores, năo como mais uma entre outras formas de compreender o mundo que nos rodeia - sem dúvida, a de maior prestígio -, mas a única. Segundo Lorenzetti e Delizoicov (2001, p. 8), a alfabetizaçấo científica que eles propóem "preocupa-se com os conhecimentos científicos, e sua respectiva abordagem, que sendo veiculados nas primeiras séries do ensino fundamental, se constituam num aliado para que o aluno possa ler e compreender seu universo". Ao que parece, para esses autores, uma leitura de mundo que năo seja a da ciência năo é considerada válida e deve ser esquecida do lado de fora da sala de aula. 
Attico Chassot (2003) é o autor com maior número de citaçóes entre os trabalhos sobre alfabetizaçáo científica. Ele critica o ensino voltado para a memorizaçâo de teorias, conceitos e processos científicos como a taxonomia, na biologia, as configuraçóes eletrônicas, na química, ou as fórmulas, na física - tipo de conhecimento, segundo ele, fadado ao esquecimento após as provas de avaliaçăo. Chassot (2003, p. 99) defende um ensino que mostre năo apenas os benefícios da ciência, mas também sua face controversa. No entanto, a sua definiçâo do termo que pressupóe a falta de conhecimento científico reflete a visăo de que, para esse autor, esse tipo de conhecimento seria o único válido: "ser alfabetizado cientificamente é saber ler a linguagem em que está escrita a natureza. É um analfabeto científico aquele incapaz de uma leitura do universo" (CHASSOT, 2003, p. 91).

O posicionamento dos autores que tratam de letramento científico, nesse aspecto, é diferente. Soares e Coutinho (2009, p. 4) observam que "a linguagem científica, assim como a linguagem específica de outras áreas, possui recursos lexicogramaticais particulares", os quais, segundo eles, "codificam conhecimentos, valores e visăo de mundo específicos da comunidade científica". Ou seja, trata-se de uma entre várias possíveis visôes de mundo. Amaral, Xavier e Maciel (2009, p. 112) alertam: "ao nâo vincular os conhecimentos científicos com os conhecimentos prévios dos alunos, contribui-se para a construçăo de uma imagem errônea da ciência, como verdade absoluta, além de tornar-se um obstáculo no processo de apropriaçâo do conhecimento".

\section{CONCLUSÃO}

Embora o número total de resultados da busca por "letramento científico" no Google Acadêmico seja praticamente cinco vezes menor do que os resultados da busca por "alfabetizaçấo científica", quando se trata da centralidade dos termos "alfabetizaçấo" e "letramento", evidenciada pelo seu uso no título, no resumo ou nas palavras-chave, o número de publicaçôes no período de 2007 a 2016 praticamente se equivale, e é evidente o crescimento dos trabalhos sobre "letramento científico" nos últimos três anos.

Esse dado sugere que é crescente a imersăo de pesquisadores dos campos da educaçăo científica e do ensino de ciências no campo do conhecimento do qual eles tomam emprestado o termo que é central para a discussăo que se propóem a fazer. Essa ampliaçăo dos horizontes teóricos e do diálogo com outras áreas é comum no nível de doutorado, em que está a maioria dos autores que tratam de letramento científico e que citam trabalhos dos estudos da linguagem. Seria fundamental se esse diálogo se desse também nos níveis de mestrado e de graduaçăo, evidenciando no campo da educaçâo científica a centralidade que o termo dos estudos da linguagem tem para esse tipo de discussăo. 


\section{REFERÊNCIAS}

AMARAL, Carmem Lúcia Costa; XAVIER, Eduardo da Silva; MACIEL, Maria DeLourdes. Abordagem das relaçóes ciência/tecnologia/sociedade nos conteúdos de funçôes orgânicas em livros didáticos de química do ensino médio. Investigaçôes em Ensino de Ciências, v. 14(1), p. 101-114, 2009.

CHASSOT, Attico. Alfabetizaçăo científica: uma possibilidade para a inclusâo social. Revista Brasileira de Educaçâo, v. 8, n. 22, p. 89-100, jan./abr. 2003.

CUNHA, Rodrigo Bastos. Os trabalhos sobre alfabetizaçāo e letramento científico: o diálogo com os estudos da linguagem na apropriaçấo de conceitos por pesquisadores do ensino de ciências. In: Reuniâo Anual da SBPC, 2015. Anais da 67ª Reuniāo Anual da SBPC, Sâo Carlos (SP), 2015. Disponível em: http://www.sbpcnet.org.br/livro/67ra/resumos/resumos/3874 1f0b7cffbb168400a0649e3057aca8186.pdf. Acesso em: 14 jun. 2017.

CUNHA, Rodrigo Bastos. Alfabetizaçăo ou letramento científico? Interesses envolvidos nas interpretaçóes da noçáo de scientific literacy. Revista Brasileira de Educaçáo, v. 22, n. 68, p. 169-186, jan./mar. 2017.

KLEIMAN, Angela Bustos. Modelos de letramento e as práticas de alfabetizaçăo na escola. In: _. (Org). Os significados do letramento: uma nova perspectiva sobre a prática social da escrita. Campinas: Mercado de Letras, 1995. p. 15-61.

LORENZZETI, Leonir; DELIZOICOV, Demétrio. Alfabetizaçăo científica no contexto das séries iniciais. Ensaio - Pesquisa em Educaçâo em Ciências, v. 3, n. 1, p. 1-17, jun. 2001.

NORRIS, Stephen P.; PHILLIPS, Linda M. How literacy in its fundamental sense is central to scientific literacy. Science Education n. 87, p. 224-240, 2003.

POSSENTI, Sírio. A leitura errada existe. In:BARZOTTO, V.H. Estado de leitura. Campinas (SP): Mercado de Letras, 1999, p. 169-178.

SANTOS, Wildson Luiz Pereira dos. Educaçăo científica na perspectiva de letramento como prática social: funçôes, princípios e desafios. Revista Brasileira de Educaçâo, v. 12, n. 36, p. 474-550, set./dez. 2007.

SILVA, Ezequiel Theodoro da. Unidades de leitura - trilogia pedagógica. Campinas (SP): Autores Associados, 2003.

SILVA, Ezequiel Theodoro da. Uma reflexâo sobre o ato de ler. 1979. Tese (Doutorado em Educaçăo) Faculdade de Educaçăo, Pontifícia Universidade Católica de Sâo Paulo (PUCSP), Săo Paulo, 1979.

SOARES, Adriana Gonçalves; COUTINHO, Francisco Ângelo. Leitura, discussāo e produçâo de textos como recurso didático para o ensino de biologia. Revista Brasileira de Pesquisa em Educaçâo em Ciências, v. 9, n. 2, p. 1-22, 2009.

SOARES, Magda. Letramento: um tema em três gêneros. Belo Horizonte: Autêntica, 1998.

Recebido em novembro de 2017.

Aceite em fevereiro de 2018. 